\title{
Badge of honour? An exploration of the use of digital badges to support a partnership approach to faculty development
}

\author{
Angelica Risquez \\ Centre for Transformative Learning, University of Limerick, Ireland \\ Dara Cassidy \\ Online Education, Royal College of Surgeons, Ireland
}

\section{Gearóid Ó Súilleabháin}

Department of Technology Enhanced Learning, Cork Institute of Technology, Ireland

\begin{abstract}
This article describes a professional development initiative facilitated through a transformational partnership model. In this context, we discuss our experience of piloting an online continuing professional development course in the area of online teaching, which offered a digital badge for successful participants. The course was the result of a partnership between three Irish higher education institutions and a national agency that had initiated a nation-wide scheme to create and disseminate a range of open access collaborative professional development courses to promote the professionalisation of teaching and learning, with a specific digital badge being available for each course. We investigated the interplay between the digital badge issued for the course we piloted, and other potential intrinsic and extrinsic motivators. Digital badges appear to be a weak motivating factor in initial enrolment and engagement, although for some participants, they did motivate continued engagement and completion. We discuss implications in relation to internal and external drivers and motivations around professional development. We also offer reflections on the larger context in which badges might be used or valued by course participants in their professional environments.
\end{abstract}

\section{Implications for practice or policy:}

- For digital badges to motivate learning, educational developers and institutions need to associate them with intrinsically meaningful rewards.

- Partnership between higher education institutes and non-accrediting bodies can drive the development and wider acceptance and use of digital badges as a tangible and agreed currency of learner and learning achievement.

- Learners benefit most from digital badges when they are linked to and facilitate the development of personal identities associated with disciplinary and professional communities.

Keywords: continuing professional development (CPD), digital badges, micro-credentials, online teaching, higher education partnerships

\section{Digital badges: Pros and cons from the literature}

In recent years, digital badges have been appropriated in formal and non-formal education settings as a way to provide visible identifiers for skills and abilities gained (Roy \& Clark, 2019). They are part of a wider trend towards the use of gamification - "the use of game design elements in non-game contexts" (Deterding et al., 2011, p. 9) - in education, most commonly in online learning but also for conventional face-to-face and blended learning across a number of levels and subsectors of education and training. A digital badge, in this context, can be defined as "a representation of an accomplishment, interest or affiliation that is visual, available online, and contains metadata, including links that help explain the context, meaning, process and result of an activity" (Gibson et al., 2015, p. 404). Rewards such as badges enhance motivation by providing a visible and tangible reward for achievements (Anderson et al., 2013). Elliott et al. (2014) argued that digital badges can also allow for a more holistic view of educational achievement than formal academic credentials do. Moreover, digital badges afford an opportunity to recognise skills that are often overlooked or taken for granted (Dyjur \& Lindstrom, 2017). Fields (2015) highlighted their usefulness for continuing professional learning development in emerging or rapidly developing fields in which formal academic 
programs may not be able to keep pace. Thus, digital badges have been extolled for their ability to increase engagement (Roy \& Clark, 2019), motivate learners (Abramovich et al, 2013; Gibson et al, 2015; Jovanovic \& Devedzic, 2015), recognise and validate informal learning (Law, 2015), support alternative forms of assessment (Hrastinski et al., 2018), chart learning routes and support self-reflection (Jovanovic \& Devedzic, 2015).

The relationship between badges and learner motivation (Wheeler, 2020) is not a straightforward one. A systematic review by Roy and Clark (2019), encompassing 23 empirical studies of digital badges conducted between 2012 and 2016, found that teacher or staff professional development was the most common focus of the non-formal studies included. The study identified five themes across the research: engagement, skills recognition and transferability, personalised learning, personal empowerment and work focus. While the review found that digital badges were reported as encouraging engagement in learning, there was no consensus on whether they also encouraged task completion (Roy \& Clark, 2019, p. 2631). However, a study by Dyjur and Lindstrom (2017), which examined the perceptions of higher education (HE) instructors engaged in a professional development program, found that the instructors generally considered that badges motivated them to complete the work of the program.

Further research has highlighted the importance of the pedagogical design underpinning professional development interventions in relation to the achievement of digital badges. For example, a study by Hrastinski et al. (2018) showed how courses that are credentialed, using digital badges, can be used to target specific issues of professional development. Their study explored whether digital badges could serve as an extrinsic motivator for online tutors to engage in specific research-informed strategies that had been found to enhance student understanding and learning. The tutors were required to produce evidence of where they had used these strategies in their interactions with students as part of an online mathematics tutoring course and write an accompanying reflection in order to earn the related digital badges. The study revealed that the process of scrutinising their interactions for examples of good practice and then reflecting on those examples in order to earn the badge was valuable for the tutors' development and gave them a more detailed understanding of the tutoring process.

Dyjur and Lindstrom (2017) found that a majority of HE instructors who had undertaken a professional development program that incorporated digital badges found them to be generally positive, authentic and innovative. One interviewee stated that because the digital badge provided more detailed information on criteria for attainment than a paper certificate, it increased the tangibility and transparency of the accomplishment. However, a substantial minority of the participants in their study stated that they did not feel that the digital badges were authentic, which the authors hypothesised could be linked to concerns from participants that the badges would not be recognised outside the context of the course. Interestingly, the badge design was another factor that appeared to influence perceptions. Participants expressed the opinion that the badges needed to look distinguished in order to have credibility. The study found that while many participants were motivated by the badges, their motivation was linked to other factors such as career progression, new job opportunities or professional development. Participants reported including their digital badge on their professional portfolio, performance reviews, professional-focused social networking sites and portfolios that would be sent to potential employers. Some participants, however, were unfamiliar with the concept of a digital badge and had no idea of how they might use it.

It would appear overall that digital badges have not yet gained widespread acceptance as academic and professional development currency. Roy and Clark stated that they have the capacity "to change the educational landscape of the future" $(2019$, p. 2633) but concluded that in order for them to become relevant outside of the learning environment in which they were earned, there needs, among other things, to be greater awareness of their potential by employers (Roy \& Clark, 2019).

Although research exists on the use of digital badges as a means of recognising engagement with continuing professional development (CPD) of HE educators (Dyjur \& Lindstrom, 2017; Jones et al., 2018), it should not be unquestionably inferred that these practices and findings will transfer to other contexts. In this article, we discuss our experience of piloting digital badges as a means of recognising CPD in HE and within the framework of a partnership model at national level. We offer reflections on the larger context in which badges might be used or valued by course participants in their professional environments. 


\section{The partnership model in Ireland: The role of the National Forum as an external driver for change}

The value of partnerships for HE institutions (HEIs) have been well rehearsed, with partnerships enabling institutions to fulfil ambitions that they may not be able to achieve alone, including cost reduction, innovation, enhanced efficiency reputation and increased enrolment (Chou, 2012). Butcher et al. (2011) distinguished between transactional partnerships, in which each partner focuses on their own goals with little regard for shared purpose, and transformational partnerships, which foster genuine engagement and focus on shared goals and mutual benefit. Our research describes a collaborative and symbiotic relationship between three HEIs and a national agency that was very much in the spirit and tradition of a transformational partnership.

In the context of the HE sector in Ireland, the National Forum for the Enhancement of Teaching and Learning (henceforth, the National Forum) was established in 2012 to provide an "academically led platform" through which to channel targeted investment into teaching and learning enhancement in HE (Henard, 2017, p. 4) and contribute towards the professionalisation of teaching in HE. With stakeholders that include public and private HEIs, state agencies and government departments, the intention was to stimulate grassroots engagement across the HE sector to collaboratively identify paths towards quality improvement. The National Forum's establishment was prompted by the recognition, as acknowledged in the National Strategy for Higher Education 2030 (Higher Education Authority, 2011), that while advances had taken place in teaching and learning in Irish HE, there was a lack of consistency and uniformity across the sector in general. The National Forum was conceived as a way to introduce a partnership approach to change, where the expertise and work of multiple stakeholders would converge in supporting the development of a consensus on multiple known and emerging issues pertaining to the enhancement of teaching and learning in Irish HE. Through this approach, the National Forum is intended to foster greater collaboration among these stakeholders, driving innovation through a partnership model rather than by taking a regulatory or quality assurance role. However, one major limitation of the National Forum's activities pertains to its reach beyond the community of teaching and learning practitioners and innovators. There is a risk that the National Forum mobilises only those already convinced of the need for the enhancement of teaching and learning, who have already experimented and pursued projects in the field.

In common with many other European countries, the Irish HE sector has traditionally not placed a strong focus on the development of faculty members' pedagogical skills, and there is no nationally mandated requirement to obtain a formal teaching qualification or to engage in teaching enhancement activities (Gaebel et al., 2018). Academic recognition moreover is typically based on research output, meaning there is little extrinsic motivation to engage in teaching and learning-focused professional development, which is not typically linked to progression or career pathways. As a result, engagement in accredited formal CPD related to teaching and learning tends to be engaged in by a relatively small - albeit growing - minority on a voluntary basis in many of Ireland's HEIs. The success of the National Forum depends upon its capacity to stimulate pedagogical engagement amongst staff who teach, and who are often either unaware of the potential for, or are reluctant to engage in, proactive teaching quality improvement (Henard, 2017). As a response, in 2016 the National Forum started the open course initiative, in close collaboration with the HE sector, to create a means of recognising and acknowledging those committed to ongoing professional development in teaching and learning. In 2017, the National Forum issued a competitive call to all HEIs to participate in the development of open courses, intended to address a series of competencies on the dimensions of the National Forum's recently developed professional development framework for all who teach in HE in Ireland (National Forum, 2016). The three participating institutions represented in this study responded to the call under the specific topic of digital capacity, and the National Forum coordinated their collaboration and funded the development of the course. The National Forum led a quality assurance process of the course contents and provided general guidelines to guarantee the consistency and integrity of all open courses. There was also an element of cross-communication with other institutions who were developing other open courses as the National Forum organised several meetings and discussion events on the development and, later, the roll-out of these open courses. Furthermore, there was a significant amount of informal communication between open course teams as institutes, and sometimes individuals, tended to be involved in more than one open course project at a time. 
The notion and spirit of partnership also extends to the implementation and validation of the National Forum's open courses, as it is built on common trust, relying on the participants to peer evaluate their respective evidence of engagement in the courses in order to qualify for a digital badge. In doing so, this partnership aims to deliver on the National Forum professional development framework aspiration for professional communication and dialogue in teaching and learning, which:

Recognises the importance of teaching and learning in a community to enhance student learning. The social dimension of professional learning is emphasised, and it recognises the role that communities of practice and networks play in supporting this locally, nationally and internationally; and within and across disciplines. (National Forum, 2016, p. 5)

Thus, the open courses are to be designed with built-in opportunities for participants to interact and engage throughout the delivery of the course in the manner reminiscent of a community of inquiry approach (Garrison et al., 2000).

Another unique feature of this partnership is its cascading model of delivery, which enables those undertaking the course to subsequently undertake facilitator training to qualify to deliver the full, badged course to other cohorts within their own institutions: in this way, anyone undertaking the course can facilitate it in the future, spreading and disseminating the course virally throughout the sector (National Forum, 2019). Throughout, the National Forum provides a tangible mark of achievement that relies on an ethos of common trust and sustainability. All courses additionally are truly open as per the 5Rs criteria for open educational resources (Wiley \& Hilton, 2018): retain (the course is openly available for download in the National Forum portal); reuse (each new facilitator can use it for their own purposes); revise (facilitators can adapt and modify to localize to their context, while preserving the criteria for the course); remix (institutions can adopt the courses that suit their needs); and redistribute (the course is shared back to the community).

The first phase of the digital badge initiative saw the design of 15 open-access courses associated with national digital badges (National Forum, 2017). These courses were developed by experts in a variety of institutions through the guidance of the National Forum and approved against nationally agreed criteria, thus enabling staff to achieve recognition and mobility within their professional development journey and career advancement. Each course requires approximately 25 learner effort hours, which may include workshop-based and independent learning. Typically, several learner activities have to be successfully completed in order to qualify for the badge with these activities being mapped to, or aligned with, the criteria set out for each badge. This initiative was innovative because until then digital badges had not been promoted or embraced at the national level. This brought about a change in the way Irish institutions plan and deliver CPD to their academic cohorts. For the first time, the Irish HE sector shared a common CPD currency with national recognition and potential transferability, while having the opportunity to engage in the collaborative shaping of these open offers in partnership with an external stakeholder. The fact that the National Forum was providing the micro-accreditation conferred a greater level of authority and recognition to the digital badge than a single institution or an external vendor could. Also, in the context of the national push towards the professionalisation of teaching in $\mathrm{HE}$ and alignment with the professional development framework, the National Forum badge promises to provide transferable evidence of CPD for those aiming for inter-institutional mobility. It was anticipated that the National Forum Digital Badges initiative could foster academic growth, professional development and career advancement in the HE sector by turning unaccredited CPD into a commonly recognised digital badge system, and therefore, would work as an external motivator for engagement by the HE teaching community. As of 2020, a total of 33 badges have been created, and a total of 888 badges earned. However, it is unknown to what extent digital badges as a national CPD currency have driven participation in the National Forum-led CPD series and what role they have played in motivating staff to complete CPD opportunities.

This article reports on our investigation on the extent to which digital badges may have worked to embed an element of extrinsic motivation in one of the CPD open courses, which was developed as a partnership between three particular HEIs and the National Forum. 


\section{Getting started with the online teaching National Forum open course}

This article reports on the delivery and evaluation of one of these professional development courses, which was intended to develop capacity in the area of online teaching. The National Forum partnered with us, employees of three Irish HEIs that are very diverse in nature: Hibernia College - a private online HE college based in Dublin; University of Limerick - a large public university, and Cork Institute of Technology - one of the largest institutes of technology, based in the south-west of the country. The three Irish HEIs applied for and received funding from the National Forum to develop a CPD offering titled "Getting Started with Online Teaching" for academics and teaching staff in the Irish HE sector. The course was designed as fully online and intended to guide participants through the process of curriculum and instructional design for an online environment, and in doing so, was intended to help lecturers build their confidence and experience and develop their own online teaching style and approaches. The course was preceded by a pre-course orientation to set expectations around engagement, which, common to other badged National Forum open courses, requires a commitment of about 25 hours, with this broken down, in our case, into webinar participation, engagement in discussion forums, individual research and the production of digital artefacts. By the end of the course, participants were expected to have developed an understanding of the student perspective of what it is like to study online, applied principles of online module design including a range of assessment options, developed online activities and open education resources and approaches to media creation, and experienced online facilitation and interaction including strategies for engaging students in the online space. These themes were facilitated on a weekly basis through synchronous interactive sessions and asynchronous "e-tivities" (Salmon, 2013) that emphasised peer collaboration and feedback. During the process, participants worked on the plans for their teaching innovation in an online environment and produced materials that would be used in their own online courses. At the end of the course, participants were expected to engage in a process of triad peer evaluation, which was a key element of being awarded the digital badge. The peer evaluation process was overseen by the course developers. The 8-week course was a notable success in terms of its popularity, its positive reception and mainstream impact; it is now being offered as mainstream CPD across several Irish HEIs.

\section{Research aim}

In the context of a growing but fragmentary body of literature on the effectiveness of digital badges as an effective extrinsic motivator for participation in academic CPD, we explored the motivations that underpinned participation in the "Getting Started with Online Teaching" open course and engagement with the process of producing evidence to attain the digital badge. This study set out to explore the interplay of digital badges with other (intrinsic and extrinsic) motivating factors to actively participate in an academic CPD offering developed as a partnership between three HEIs and the National Forum.

\section{Methods}

A basic mixed methods approach was used to investigate the research question outlined above, within the context of a wider discussion on the impact that the course had on the participants' knowledge, understanding of and attitudes towards online teaching. Data gathering methods consisted of pre- and postsurveys and three focus groups. The pre- and post-survey were used to gather largely quantitative data about participant characteristics, motivations, learning goals and outcomes and changes in beliefs and attitudes about online learning over time. The focus groups enabled us to probe more deeply into the responses with an emphasis on obtaining richer qualitative data on the role of the digital badge accreditation in motivating participation and engagement. The use of these mixed approaches represented a deliberate effort at methodological triangulation and an attempt to examine the experiences, motivations and outcomes of our learners from multiple data sources.

The participants in this study consisted of 24 female and 13 male staff members from 9 institutions across the country and were a mix of discipline-based lecturers, educational developers and/or technologists. Roughly half had at least some experience with online teaching prior to undertaking the course. All but one of the 37 participants who were offered a place in the course consented to take part in the research and completed the pre-course survey, while 26 responded to the post-course survey (representing $76 \%$ of the 34 participants who completed the course and who submitted their evidence for the badge). 
Survey data, as indicated, were used to provide a largely quantitative overview of participant characteristics, motivations and changes over time - analysis was in the form of descriptive statistics as the sample size did not provide the normal distribution required for any inferential statistical measures. These basic descriptive statistics were counterbalanced by a wealth of qualitative data collected from the focus groups on completion of the course. A thematic analysis of the qualitative focus group data was undertaken based on guidelines from Braun and Clarke (2006), which proved helpful as an essentialist or realist (Roulston, 2001) orientation, meaning it provided a way to focus on the assumed reality evident in the data, as opposed to a more deductive orientation whereby coding and theme development might be more dictated by existing concepts and ideas. This essentialist and realist epistemological approach enabled us to theorise motivations, experience and meaning in a straightforward way, because a simple, largely unidirectional relationship was assumed between meaning and experience and language (Braun \& Clarke, 2006, p. 85). This approach gave rise to the identification of five main semantic themes (motivations to participate, engagement with the course, impact on the participant, impact on practice and other benefits). The text was double-coded hierarchically into two sublevels by one of the authors and an independent researcher. Confirmation bias was controlled firstly by discussing coding when disagreements occurred, and secondly by confirming the coding with the two other authors, who had not previously taken part in the thematic analysis.

Participation in the research phase of this course was always voluntary, and responses were reported anonymously. Ethical clearance was obtained through Hibernia College, and this ethics approval was recognised by the other participating institutions.

\section{Results}

\section{Pre- and post-survey results}

The results of the pre-survey revealed that 31 participants $(86 \%)$ had experienced online teaching as a student, while 24 (67\%) had experienced it as an educator. When asked about their digital confidence levels, $20(55.5 \%)$ rated it as high or very high, $14(38.8 \%)$ rated themselves as neither high nor low, and $2(5.5 \%)$ rated themselves as low or very low. In response to the free-text questions about what motivated respondents to participate, the main reasons given related to a general desire for professional development. Significantly, only two respondents spontaneously mentioned the digital badge that was associated with the course, which was interesting in itself (the focus groups probed into the motivating role of the digital badge in detail). In response to the free-text question "What do you want to achieve on the course?", most participants referred to enhancing their knowledge of learning design for the online context. Participants also expressed a strong interest in learning how to develop content for online delivery and finding out more about engaging students online. Others referred to planning, assessment delivery and support. One person said they saw the course as a potential means to develop a support network that might extend beyond the duration of the course itself.

A total of 26 participants responded to the post-course survey. Asked about their satisfaction with the course, all 26 said they were satisfied (42\%) or very satisfied (58\%). Participants were also asked how well they thought the teaching methodologies used in the course aligned with its purpose. Again, the response was very positive with $12(48 \%)$ rating them effective and $11(44 \%)$ rating them very effective, while 2 people ( $8 \%$ ) were unsure (1 missing answer). Asked whether they thought they would implement anything that they learned in the course, all stated that they planned to. A follow-up free-text question probing more detail on this response identified the practice and experience of using various tools, the overall enhanced knowledge of what's involved in online and blended learning, the confidence they gained from participating in the course, and the alignment with their more general plans to deliver online/blended courses, as the main benefits referred to. When asked about what they liked best about the course, the majority of the 23 respondents referred to the design and structure of the course in general. The discussion forum and the focus on tools were the next most widely referenced items. When asked what they disliked, by far the most common complaint was lack of time (12 mentions) - this covered a few different issues - the timing of the course and the workload involved. Many of the participants felt under time pressure from their jobs and felt this impacted their ability to engage fully with the course. The next most common negative points raised regarded a lack of student-student interaction (3 respondents) and references to specific tasks that the participants did not enjoy ( 3 respondents). When asked about enhancements for future iterations, the most 
common request (6 participants) was for a detailed calendar at the start of the course that would include dates and times for all webinars and deadlines for all activities. The next most requested change (4 participants) was for more flexibility regarding the timing of the course, followed by a greater focus on encouraging student-student participation. All those who responded to the post-course survey (26 respondents) said they would be claiming their digital badge.

\section{Thematic analysis of focus groups}

The results of the thematic analysis of motivations to participate in this course clustered around either extrinsic or intrinsic drivers, and was represented in equal measure, as can be observed in the table below.

Table 1

Results of the thematic analysis of motivations to participate in the course

\begin{tabular}{cc}
\hline Theme and subcodes & References \\
\hline Extrinsic & 0 \\
Evidence CPD and accreditation (digital badge) & 12 \\
Incentives, pressures and relevance to practice & 14 \\
Intrinsic & 0 \\
Development of theoretical knowledge and practice on online teaching & 4 \\
Exposure to and modelling of online teaching & 5 \\
Exposure to new technologies and learning new digital skills & 3 \\
Personal interest and convenience & 12 \\
\hline
\end{tabular}

Closely related to motivations to participate, a series of themes revolved around the participants' engagement with the course. These included the following: their commitment and approach to participation (which ranged from the more strategic to those who engaged at a very deep level); challenges to engagement, including a perceived high workload associated with the course tasks; insights on the development of a community of inquiry throughout the course, which was perceived by many to be the most positive and distinctive characteristic of this course; their experiences with the tools or platforms (both positive and negative); and the importance of teaching presence, which was at the core of the community of inquiry. Others appreciated the opportunity to network between institutions and declared their increased awareness of the National Forum resources and initiatives.

In a few cases, the digital badge proved to be a strong extrinsic motivator for participation and completion:

It was a significant motivation for me, that there was some sort of, you know, microcredential, or credential at the end of it, and I will certainly be claiming it [laughs] after putting all the effort into submitting the evidence for it. I think it's a very valuable thing for CPD to have some sort certification or credential at the end of it, whatever it is, via digital badge or some sort of credit system, I do think it's a very motivating factor for [HE lecturers].

The impetus, or the focus, from having effectively a nationally recognised qualification of some kind, or award or some kind - absolutely is a motivational thing. I mean there were times, as come up in previous questions, where, you know, the pressure was on because of work commitments, and if there wasn't a driver like CPD points or the teaching online badge, it would have made it all too easy to just walk away and say 'oh I have to prioritize here, and this isn't that important'. So, em, there's no doubt the focus of the end game kept its importance to the forefront.

Two participants had some knowledge and concrete ideas regarding the purpose and use of their digital badge:

I don't have a blog portfolio as yet, I'm planning on one, but I do have an Open Badge passport account, and any of the professional development that I do, I try to display the digital badges that I earn, I'd hopefully also be able to display it on maybe LinkedIn social media accounts $(. .$.$) as evidence of attainment of certain credentials from professional development$ opportunities I undertake. 
With regards to the badge, I suppose that it is nice to have something (...) I have some online presence in LinkedIn and I will be uploading the badge on that.

However, in other cases, participants were not particularly motivated to gain the digital badge:

I don't think the actual badge or the idea of getting some kind of an award for completing the course was a motivating factor. So, I think it was just more that it looked like a really practical course to do, and as I mentioned, sort of, at the right time for me.

Although not a critical motivator for participation, a number of the participants still acknowledged the value of having some level of recognition for their engagement with CPD, as in this selected quote:

It wasn't the badge that attracted me, it was the content. But having said that, it is quite nice to have the badge now, so, as you go forward with online teaching, blended learning areas you can actually say I have some experience.

In several cases, although the motivation driver was primarily intrinsic, participants stated that having an element of extrinsic recognition through the micro-credential provided some additional encouragement to complete the course:

Improve my skills, that was the main motivation. I suppose that yeah - students tend to think of accreditation first, and I suppose [the online badge] became a driver during the course, to be able to show that I have done it, that kept the motivation going.

Some comments pointed to the fact that there is no culture of recognition of micro-accreditation of CPD amongst university teachers. Confusion of terms was common: when talking about the digital badge, participants often did not refer to the micro-credential, but to the course itself. Others did not actually know what we were referring to at all:

Apologies for my ignorance of what exactly the badge is. Is it something I'm going to add to my email signature, or, you know, do I want to put it on the door? I've no idea, to be honest with you. All donations gratefully received if we do get it. I look forward to seeing what it is.

Some comments indicated that the level of extrinsic motivation that was associated with the digital badge was dependent on the level of familiarity with this type of micro-credential:

In contrast to the other [participants in the focus group discussion], for me it was actually quite a motivation. But I guess we use badges a lot, so we're quite heavy users of badging, so maybe it's because I have slightly more awareness of it.

In this direction, another participant more versed with this type of micro-credential wanted to contribute to building a culture of the value of CPD through digital badging:

The plan would be to try and roll it out within my own institution (...) I don't think that because I have undertaken this sort of professional development that now I've landed on the higher cloud of 'I am all singing, or dancing, I know it all'. I don't, but it gives me a chance, and a bit of a confidence to try and bring more people on board to the whole idea of the digital badge system.

\section{Discussion and conclusions}

Three diverse Irish HE institutes collaborated to design, develop, deliver and evaluate an online CPD course for academics taking their first steps with teaching. This work was carried out in partnership with an external stakeholder (Ireland's National Forum), which brought about a new focus on nationally recognised digital badges as a way to encourage and recognise the professional development of those teaching in HE. The results of the survey conducted at the end of the course suggest very high satisfaction rates with the course. Significantly, all the survey respondents indicated plans to implement what they learned on the 
course, suggesting a high probability for learning transfer. Similarly, $80 \%$ of survey respondents claimed the course had changed the way they think about online learning, and all respondents indicated the course had increased their knowledge and confidence in the area. A survey conducted before the rollout of the course provided data regarding participant motivation, which mapped well to related questions in the postsurvey and a participant focus group. On completion, all participants claimed the available digital badge from the National Forum. The badge's function as an external motivator came up during the focus groups and in post-survey comments, but significantly, it did not feature particularly strongly. Likewise, the digital badge did not receive much prominence either as an initial motivator in the pre-survey (with only 2 of the 36 respondents mentioning it). Interestingly however, although not a crucial motivator for initial engagement for most participants, the digital badge served as a motivator for engagement and completion for time-poor academics, and some recognised its currency in terms of CPD. Arguably, the sample was not representative of the general academic population but of a substratum who volunteered to participate because of their personal interest. Yet, our findings rely largely on qualitative data and are intended to provide a window to understand the experience of a specific group in a specific context. When transferring findings, the reader should consider that the participants in this investigation may be less likely to have been motivated by the digital badge because their intrinsic motivation to participate was high and they were especially interested in the kind of practices that the course was explicitly intended to help them with.

It is suggested in the literature that extrinsic rewards can conflict with or diminish intrinsic motivation (see, e.g., Deci et al., 1999), which is something we were cognisant and wary of, so this finding was not seen as a negative, and the team very much welcomed the alternative emphasis being placed by participants in both the post-survey and focus groups on other kinds of more intrinsic achievement such as gaining knowledge, confidence and attitude. The team also grappled with the issue of external validation throughout the instructional design process as we tried to develop a course that would serve as a national standard for preparing HE teaching staff for online delivery. We felt that an emphasis on the standards-setting aspect of the course suggested an instructional design approach based on closely planned and reliably assessed learning outcomes and, although this was resisted, a tendency towards a more technical syllabus. We were keenly aware throughout the design process that an overemphasis on external standards (as recognised by the digital badge), and what might ultimately be viewed as external accountability, could work against and negatively impact participants' own capacities and opportunities for critical and reflective inquiry (Beyer, 2002), which we were keen to facilitate and encourage. The team were also eager to reject a purely training and/or transmission view of CDP or academic professional development and move at least in part towards a transformative approach that provides opportunities for unplanned learning to emerge and for attitudes, values and practice-in-context, as well as procedural knowledge and technical know-how, to be addressed. Fortunately, what emerged from the partnership between the HEIs and the National Forum in the design and the delivery of these open courses was that assessment should place more emphasis on reflective triadbased peer assessment than on a granular mapping of individual learning evidence to learning outcomes. Within this process, participants were further encouraged to discuss what came up for them and how learning emerged that went beyond what was necessarily planned and beyond what was technically procedural or even demonstrable.

The partnership model underpinning the relationship between the National Forum and the partner institutions involved in the creation of the suite of digital badges can thus be characterised as a transformative one (Butcher et al., 2011). At its core was a community of practice (Wenger, 1998) model that sought to foster a culture of professional learning with the evolutionary capacity to adapt to changing institutional circumstances and environments. Within this partnership model, the development of the digital badges provided a space where the collaborating institutions negotiated a framework to work together. The role of the individual academic staff who collaborated on the development of the badge criteria was simultaneously one of expert and learner. This dual role extended to the co-creation of the materials that were used in the development of the online course, which supported other staff to work to attain the badge, and it continued through to the delivery of the course, which was designed to extend the community of practice to academic staff beyond the original development team. In addition, we had built in opportunities for participants to interact and engage throughout the delivery of the course in a manner reminiscent of a community of inquiry approach (Garrison et al., 2000). The results and experience highlight the importance of professional dialogue for professional development and the importance of providing what Ashgar and Pilkington (2018) called dialogic opportunities and professional dialogue, as opposed to individualist approaches to CPD. Arguably, the team managed to find a middle ground between a traditional transmission-type training model offering and a transformative CPD offering with no planned outcomes, 
where learning interaction evolves in organic and unexpected ways. While some unplanned or emergent learning was evidenced in the context-rich encounters and interactions between participations of the course, this was also, as reflected, for example, by the tightly defined assessments and activities that formed an integral part of the course, a conventionally structured CPD course. This is testament to the flexibility of a pedagogical design which accommodates both structured information-transfer as well as a more reflectionbased, developmental focus, such as that adopted by Hrastinski et al. (2018) in their study of professional development for online tutors.

The research further resonated with claims that there remains a general lack of awareness among HE staff as to the purpose and potential of digital badges (Dyjur \& Lindstrom, 2017). Wheeler (2020) proposed that:

Like many other ed tech developments, digital badges had an initial flurry of interest from devotees but then settled into a pattern of more laborious long-term acceptance. They represent a combination of key challenges for educational technology: realizing easy-to-use, scalable technology; developing social awareness that gives them currency; and providing the policy and support structures that make them valuable. Of these challenges, only the first relates directly to technology, the more substantial ones relate to awareness and legitimacy. (p. 153)

Among the multiple confounding and extraneous variables impacting upon the influence of digital badges on learner motivation, the status of digital badges in the relevant work or professional environment must be considered (Roy \& Clark, 2019). Purpose, transferability and learning objectives have been offered as the top priorities in implementing badge offerings in HE (Carey \& Stefaniak, 2018). In our study, the digital badge served as branding and gave an identity to the course that distinguished it at a national level from the many massive open online courses or other courses that exist in relation to this topic. Within the partnership, the digital badges provided both flexibility and structure, serving as an external signifier of quality and a motivator for staff to engage in the professional learning opportunity offered. It served the purpose of embodying this identity, as part of the constellation of National Forum open courses, each with their corresponding digital badge. As such, the use of digital badges as an identification mechanism may be a transferrable element to other contexts characterised by transformational partnerships between different agents in the HE arena.

Clearly the extent to which badges can function as an extrinsic motivation will depend on several other variables and influences that go beyond the data and findings of this study. Variables such as life phase, previous achievements and formal qualifications, work experience, stage of the work life cycle (ascending or descending) and employment status (e.g., permanent or tenured; casual or part-time) will thwart efforts to use badges to produce universal and predictable outcomes (Grant, 2014). Hickey and Willis (2017) concluded that the use of open digital badges to motivate learning works better when they are associated with intrinsically meaningful rewards rather than extrinsic incentives, and where learning is not motivated by formal course credit; when learners are motivated by peer endorsers identified in existing communities or networks; when learners reflect on their engagement in learning rather than the outcomes of that learning; and when they are used to help learners establish personal identities associated with disciplinary and professional communities, and to motivate engagement with disciplinary and professional communities. Within this context, the transformational nature of the partnership model, encompassing opportunities for professional learning for both participants and experts, appears to be more aligned with intrinsic motivation than may be achieved by adopting more transactional approaches to partnership (Butcher et al., 2011). Within the transformational partnership approach, digital badges served a dual purpose: first, as an enabling framework to support the collaborative work of the inter-institutional team developing the professional learning activities, and second, to bestow recognition and meaning on the activities of those engaged in the professional learning opportunities.

How we define and implement pedagogical approaches will impact on the extent to which our badged CPD offerings can be about more than just traditional technicist transmission models and can also provide for open unplanned and transformative academic development. Finally, the danger that badges might work against or negatively impact intrinsic motivation needs to be examined more closely and guarded against in the way in which badges are embedded into our CPD systems. 


\section{References}

Abramovich, S., Schunn, C., \& Higashi, R. (2013). Are badges useful in education? It depends upon the type of badge and expertise of learner. Educational Technology Research and Development, 61(2), 217-232. https://doi.org/10.1007/s11423-013-9289-2

Anderson, A., Huttenlocher, D., Kleinberg, J., \& Leskovec, J. (2013). Steering user behavior with badges. In D. Schwabe, V. Almeida, \& H. Glaser (Eds.), Proceedings of the 22nd International Conference on World Wide Web (pp. 95-106). ACM. https://doi.org/10.1145/2488388.2488398

Asghar, M., \& Pilkington, R. (2018). The relational value of professional dialogue for academics pursuing HEA fellowship. International Journal for Academic Development, 23(2), 135-146. https://doi.org/10.1080/1360144X.2017.1386566

Beyer, L. (2002) The politics of standardization: Teacher education in the USA. Journal of Education for Teaching, 28, 239-245. https://doi.org/10.1080/0260747022000021377

Braun, V., \& Clarke, V. (2006). Using thematic analysis in psychology. Qualitative Research in Psychology, 3(2), 77-101. https://doi.org/10.1191/1478088706qp063oa

Butcher, J., Bezzina, M., \& Moran, W. (2011). Transformational partnerships: A new agenda for higher education. Innovative Higher Education, 36(1), 29-40. https://doi.org/10.1007/s10755-010-9155-7

Carey, K. L., \& Stefaniak, J. E. (2018). An exploration of the utility of digital badging in higher education settings. Educational Technology Research and Development, 66(5), 1211-1229. https://doi.org/10.1007/s11423-018-9602-1

Chou, D. C. (2012). Building a successful partnership in higher education institutions. International Journal of Information Systems and Change Management, 6(1), 84-97. https://doi.org/10.1504/IJISCM.2012.050350

Deci, E. L., Koestner, R., \& Ryan, R. M. (1999). A meta-analytic review of experiments examining the effects of extrinsic rewards on intrinsic motivation. Psychological Bulletin, 125(6), 627-668. https://doi.org/10.1037/0033-2909.125.6.627

Deterding, S., Dixon, D., Khaled, R., \& Nacke, L. (2011). From game design elements to gamefulness: Defining "gamification”. In A. Lugmayr, H. Franssila, C. Safran, \& I. Hammouda (Eds.), Envisioning future media environments - Proceedings of the 15th International Academic MindTrek Conference (pp. 9-15). ACM. https://doi.org/10.1145/2181037.2181040

Dyjur, P., \& Lindstrom, G. (2017). Perceptions and uses of digital badges for professional learning development in HE. TechTrends, 61(4), 386-392. https://doi.org/10.1007/s11528-017-0168-2

Elliott, R., Clayton, J., \& Iwata, J. (2014). Exploring the use of micro-credentialing and digital badges in learning environments to encourage motivation to learn and achieve. In B. Hegarty, J. McDonald, \& S. K. Loke (Eds.), Rhetoric and reality: Critical perspectives on educational technologyProceedings of the 2014 ASCILITE Conference (pp. 703-707). https://www.ascilite.org/conferences/dunedin2014/files/concisepapers/276-Elliott.pdf

Fields, E. (2015). Making visible new learning: Professional development with open digital badge pathways. The Canadian Journal of Library and Information Practice and Research, 10(1), 1-10. https://doi.org/0.21083/partnership.v10i1.3282

Gaebel, M., Zhang, T., Bunescu, L., \& Stoeber, H. (2018). Learning and teaching in the European higher education area. European University Association. https://eua.eu/downloads/publications/trends-2018learning-and-teaching-in-the-european-higher-education-area.pdf

Garrison, D. R., Anderson, T., \& Archer, W. (2000). Critical inquiry in a text based environment: Computer conferencing in higher education. The Internet and Higher Education, 2(2/3), 87-105. https://doi.org/10.1016/S1096-7516(00)00016-6

Gibson, D., Ostashewski, N., Flintoff, K., Grant, S., \& Knight, E. (2015). Digital badges in education. Education and Information Technologies, 20(2), 403-410. https://doi.org/10.1007/s10639-013-9291-7

Grant, S. (2014). What counts as learning: Open digital badges for new opportunities. Digital Media and Learning Research Hub. https://dmlhub.net/wpcontent/uploads/files/WhatCountsAsLearning Grant.pdf

Henard, F. (2017). Review of the National Forum for the Enhancement of Teaching and Learning. Learning Avenue. https://hea.ie/assets/uploads/2017/04/Review-of-the-National-Forum-for-theEnhancement-of-Teaching-and-Learning-2.pdf

Hickey, D., \& Willis, J. (2017). Where open badges appear to work better: Findings from the Design Principles Documentation Project. Center for Research on Learning and Technology. https://iu.app.box.com/s/vledf13tqnzq1tp1otcxknz7ehlkrwkr 
Higher Education Authority. (2011). National strategy for higher education to 2030. https://hea.ie/assets/uploads/2017/06/National-Strategy-for-Higher-Education-2030.pdf

Hrastinski, S., Cleveland-Innes, M., \& Stenbom, S. (2018). Tutoring online tutors: Using digital badges to encourage the development of online tutoring skills. British Journal of Educational Technology, 49(1), 127-136. https://doi.org/10.1111/bjet.12525

Jones, W. M., Hope, S., \& Adams, B. (2018). Teachers' perceptions of digital badges as recognition of professional development. British Journal of Educational Technology, 49(3), 427-438. https://doi.org/10.1111/bjet.12557

Jovanovic, J., \& Devedzic, V. (2014). Open badges: Challenges and opportunities. In E. Popescu, R. Lau, K. Pata, H. Leung, \& M. Laanpere (Eds.), Advances in web-based learning-Proceedings of the International Conference on Web-Based Learning (pp. 56-65). Springer. https://doi.org/10.1007/9783-319-09635-3 6

Law, P. (2015). Recognising informal e-learning with digital badging: Evidence for a sustainable business model. Open Praxis, 7(4), 299-310. https://doi.org/10.5944/openpraxis.7.4.247

National Forum for the Enhancement of Teaching and Learning. (2016). Professional development framework for all staff who teach in higher education. https://www.teachingandlearning.ie/wpcontent/uploads/NF-2016-National-Professional-Development-Framework-for-all-Staff-Who-Teachin-Higher-Education.pdf

National Forum for the Enhancement of Teaching and Learning. (2017). Open-Access Professional Development Courses. Retrieved from https://www.teachingandlearning.ie/our-priorities/professionaldevelopment/open-access-professional-development-courses/

National Forum for the Enhancement of Teaching and Learning. (2019). Facilitating National Forum professional development digital badge programmes. https://www.teachingandlearning.ie/ourpriorities/professional-development/open-access-professional-development-courses/facilitatingnational-forum-professional-development-digital-badge-programmes/

Roulston, K. (2001). Data analysis and 'theorizing as ideology'. Qualitative Research, 1(3), 279-302. https://doi.org/10.1177\%2F146879410100100302

Roy, S., \& Clark, D. (2019). Digital badges, do they live up to the hype? British Journal of Educational Technology, 50(5), 2619-2636. https://doi.org/10.1111/bjet.12709

Salmon, G. (2013). E-tivities: The key to active online learning. Routledge. https://doi.org/10.4324/9780203074640

Wenger, E. (1998). Communities of practice: Learning, meaning, and identity. Cambridge University Press. https://doi.org/10.1017/CBO9780511803932

Wheeler, M. (2020): 25 years of ed tech. AU Press. https://doi.org/10.15215/aupress/9781771993050.01

Wiley, D., \& Hilton, J. L. (2018). Defining OER-enabled pedagogy. The International Review of Research in Open and Distributed Learning, 19(4). https://doi.org/10.19173/irrodl.v19i4.3601

Corresponding author: Angelica Risquez, angelica.risquez@ul.ie

Copyright: Articles published in the Australasian Journal of Educational Technology (AJET) are available under Creative Commons Attribution Non-Commercial No Derivatives Licence (CC BY-NC-ND 4.0). Authors retain copyright in their work and grant AJET right of first publication under CC BY-NC-ND 4.0.

Please cite as: Risquez, A., Cassidy, D., \& Ó Súilleabháin, G. (2020). Badge of honour? An exploration of the use of digital badges to support a partnership approach to faculty development. Australasian Journal of Educational Technology, 36(5), 18-29. https://doi.org/10.14742/ajet.6112 